\title{
NUMERICAL MODELING OF AMPHIBIOUS SNOWMOBILE-GLIDER MOVEMENT ON UNEVEN SURFACE
}

\author{
Al-Maidi A. A.H \\ Plant Protection Dept. Coll. of Agriculture, University of Misan. Misan, Iraq \\ Karmanov V.P \\ Tambov regional public autonomous professional educational institution "College of \\ Equipment and Technology of Land Transport of M. S. Solntsev", Tambov, Russia

\section{Rodionov Yu. V, Muromtsev D.Y and Nikitin D.V} \\ Federal state budgetary educational institution of higher education "Tambov \\ State technical university", Tambov, Russia
}

\begin{abstract}
The paper studies the promising vehicle configurations, in particular, amphibious snowmobile-gliders (ASG) with elastic-damping cab suspension. The aim of the study is simulation of ASG dynamic loading processes when driving on uneven ground, and optimization of the elastic-damping cab suspension performance. The study was conducted by mathematical simulation on the PC such a solution requires careful calculation of the suspension parameters using the ASG mathematical model. We designed the calculation scheme and the mathematical model of dynamic loading for the ASG with elastic damping cab suspension. This approach was implemented as a software package for a PC with visualization of calculation results.
\end{abstract}

Key words: amphibious snowmobile-glider; dynamic loading; mathematical model of elastic damping suspension; optimization, the cabin and ski-wheel.

Cite this Article Al-Maidi A. A.H, Karmanov V.P, Rodionov Yu. V, Muromtsev D.Y and Nikitin D.V, Numerical Modeling of Amphibious Snowmobile-Glider Movement on Uneven Surface, International Journal of Advanced Research in Engineering and Technology, 10(3), 2019, pp. 251-258.

http://iaeme.com/Home/issue/IJARET?Volume $=10 \&$ Issue $=3$

\section{THE RELEVANCE OF THE PROBLEM.}

The harsh climate and lack of a developed road network in most parts of Siberia and the Far East have caused widespread use of different off-road vehicles, including amphibious snowmobile-gliders (ASG) with an engine of a propeller capable of moving on snow, ice, water or marshy surface. 
A major shortcoming of some designs of ASG with a rigid connection of the cabin and skiwheel system (Fig.1) is a strong dynamic activity (shakes and bumps) which occurs when gliding on the water in rough seas or driving on snow sastrugi (irregular ridges formed on snow), or moving on bumpy and rough roads. These effects cause the fatigue design and defects, lack of comfort of the driver and passengers and complicate the handling of the vehicle.

One of the possible measures to improve the ASG performance is to separate the cabin and the engine compartment from the ski-wheel system, and install the elastic damping suspension components between them (Fig.2). However, such a solution requires careful calculation of the suspension parameters using the ASG mathematical model. The lack of such a model description and an appropriate calculation method have necessitated the urgency of this research.

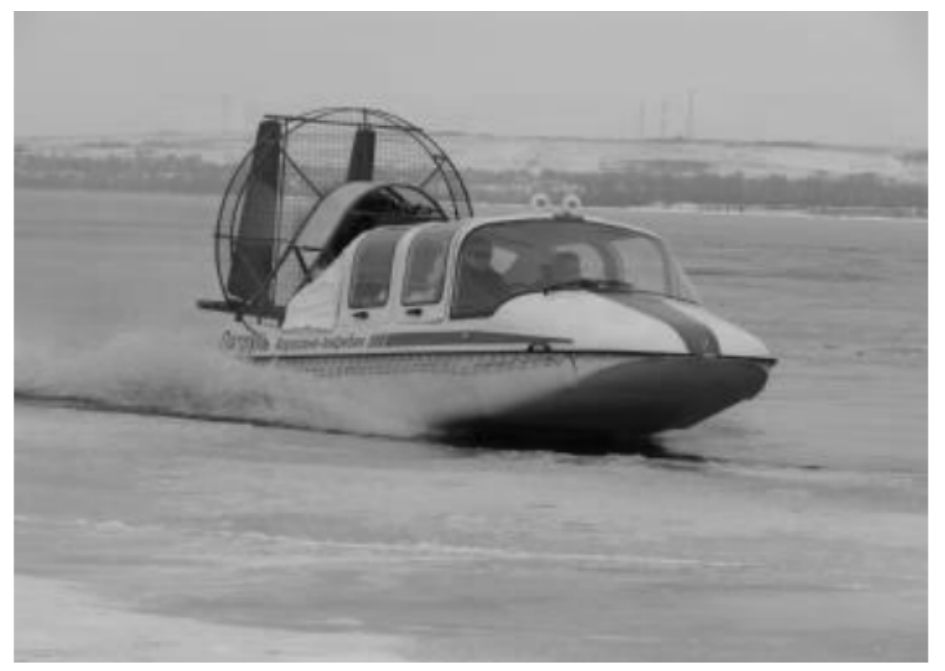

Figure 1: amphibious snowmobilegliders (ASG)

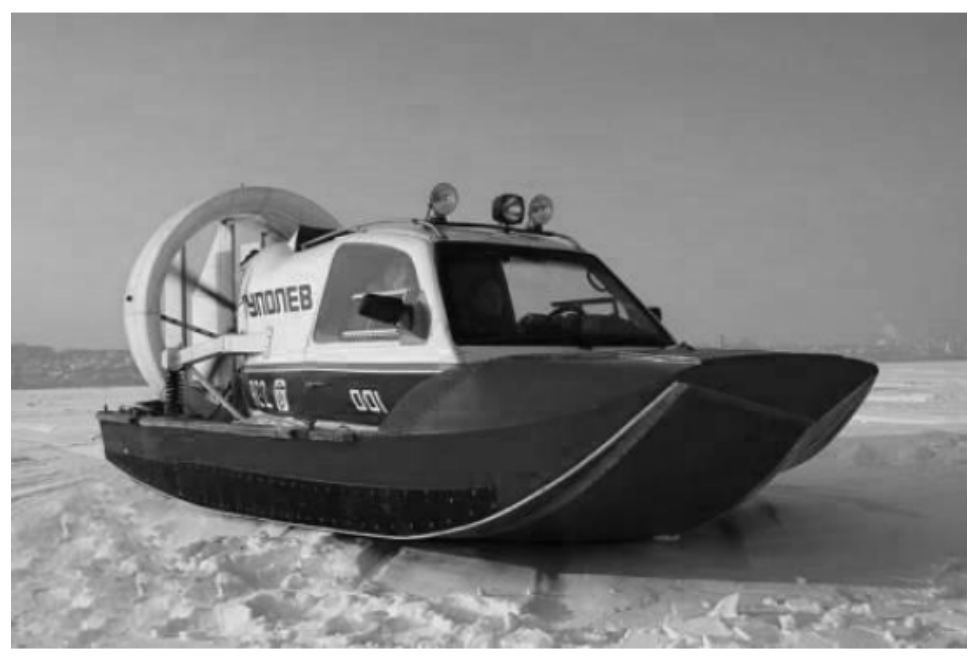

Figure 2: amphibious snowmobilegliders (ASG)

\section{A METHOD OF SOLVING THE PROBLEM.}

To solve the problem of determining the dynamic loading characteristics of the ASG when driving on uneven ground will use the numerical method based on the PC. To implement the ASG movement under the influence of an external load, depending on time, it can be described by the standard system of differential equations: 
where $\{q\}$ is a vector of generalized coordinates; $[A]$ is matrix of inertial coefficients; $[D]$ and $[B]$ are matrices of damping and rigidity coefficients, respectively; $\{F(t)\}$ is a vector of external load.

Determination of the law of ASG movement is reduced to solving the Cauchy problem for a system of differential equations [2], using the Newmark method of stable implicit difference with a second-order approximation for the first and second derivatives. The choice of the method is conditioned by its relative simplicity and wide use in the calculation of the dynamics of FEM systems, for example, in [2, 5].

$$
\begin{gathered}
\{\ddot{q}(t+\Delta t)\}=\frac{4}{(\Delta t)^{2}}[\{q(t+\Delta t)\}-\{q(t)\}]-\frac{4}{\Delta t}\{\dot{q}(t)\}-\{\ddot{q}(t)\} \\
\{\dot{q}(t+\Delta t)\}=\{\dot{q}(t)\}+\frac{1}{2}[\{\ddot{q}(t)\}+\{\ddot{q}(t+\Delta t)\}] \Delta t
\end{gathered}
$$

Where $\Delta t$ is a time integration step. This method allows us to reduce the equation (1) to a system of linear algebraic equations of the form

$$
[K]\{q(t+\Delta t)\}=\{\tilde{F}(t+\Delta t)\}
$$

Which is solved at each time integration step. The matrix and vector included in the equation (4) are determined by the following dependencies

$$
\begin{gathered}
{[K]=[B]+\frac{4}{(\Delta t)^{2}}[A]+\frac{2}{\Delta t}[D]} \\
\{\tilde{F}(t+\Delta t)\}=\{F(t+\Delta t)\}+[A]\left[\frac{4}{(\Delta t)^{2}}\{q(t)\}+\frac{4}{\Delta t}\{\dot{q}(t)\}+\{\ddot{q}(t)\}\right]+ \\
+[D]\left[\frac{2}{\Delta t}\{q(t)\}+\{\dot{q}(t)\}\right] .
\end{gathered}
$$

At the initial time when $t_{0}=0$ displacement and velocity are known, and from the differential equations of movement drawn up for $t_{0}$, the accelerations are determined

$$
\left\{\ddot{q}_{0}\right\}=[A]^{-1}\left(\left\{F_{0}\right\}-[D]\left\{\dot{q}_{0}\right\}-[B]\left\{q_{0}\right\}\right)
$$

The step process is carried out sequentially according to the formulas (5), (6) (4) (2) and (3). To solve the systems of linear algebraic equations (4) the Gauss method [1] is used. Matrix coefficients of the equation (1) are formed for ASG design scheme are based on the adopted structural layout (Fig. 3). In this case, we make the following assumptions:

- the cab with the engine compartment and the ski-wheel system are absolutely rigid, and their relationship to each other is the elastic and damping;

- the AGS movement is considered only in a longitudinal vertical plane;

- the AGS bend angles by longitudinal trim during movement are assumed as small;

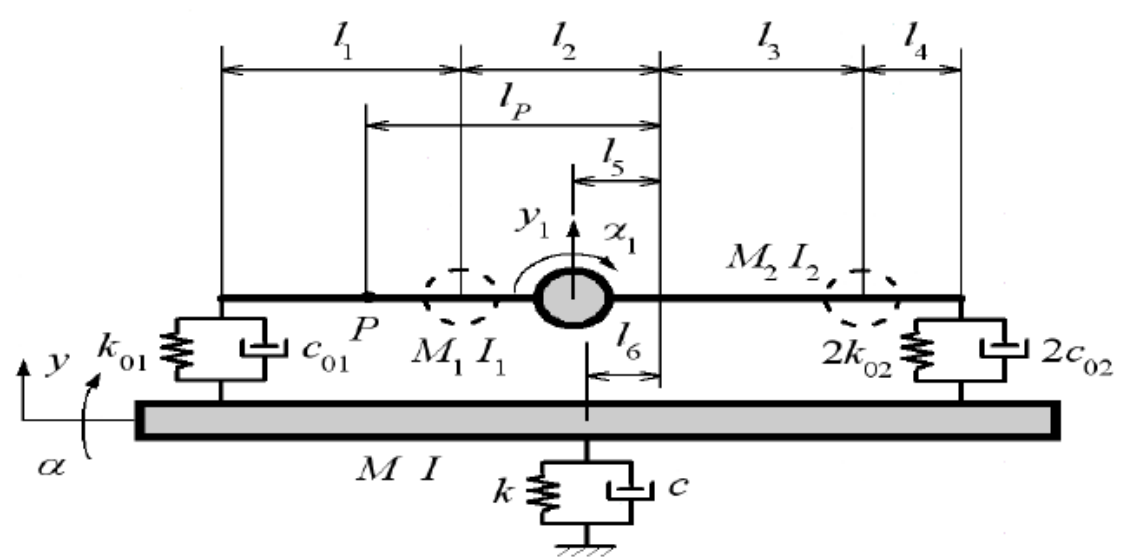

Figure 3 ASG design scheme

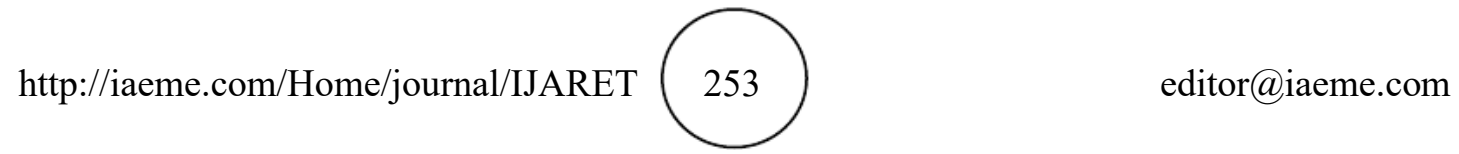


In view of the assumptions made the design scheme of ASG has 4 degrees of freedom,

$$
\begin{gathered}
{\left[\begin{array}{cccc}
M_{1}+M_{2} \\
0 & I_{1}+M_{1}\left(l_{2}-l_{5}\right)^{2}+I_{2}+M_{2}\left(l_{3}+l_{5}\right)^{2} & 0 & 0 \\
0 & 0 & M & 0 \\
0 & 0 & 0 & I
\end{array}\right]} \\
{[D]=\left[\begin{array}{llll}
d_{11} & d_{12} & d_{13} & d_{14} \\
d_{21} & d_{22} & d_{23} & d_{24} \\
d_{31} & d_{32} & d_{33} & d_{34} \\
d_{41} & d_{42} & d_{43} & d_{44}
\end{array}\right]}
\end{gathered}
$$

where $d_{11}=c_{01}+2 c_{02}$;

$$
\begin{aligned}
& d_{12}=d_{21}=c_{01}\left(l_{1}+l_{2}-l_{5}\right)-2 c_{02}\left(l_{3}+l_{4}+l_{5}\right) \\
& d_{13}=d_{31}=-c_{01}-2 c_{02} \\
& d_{14}=d_{41}=-c_{01}\left(l_{1}+l_{2}-l_{6}\right)+2 c_{02}\left(l_{3}+l_{4}+l_{6}\right) \\
& d_{22}=c_{01}\left(l_{1}+l_{2}-l_{5}\right)^{2}+2 c_{02}\left(l_{3}+l_{4}+l_{5}\right)^{2} ; \\
& d_{23}=d_{32}=-c_{01}\left(l_{1}+l_{2}-l_{5}\right)+2 c_{02}\left(l_{3}+l_{4}+l_{5}\right) ; \\
& d_{24}=d_{42}=-c_{01}\left(l_{1}+l_{2}-l_{6}\right)\left(l_{1}+l_{2}-l_{5}\right)-2 c_{02}\left(l_{3}+l_{4}+l_{6}\right)\left(l_{3}+l_{4}+l_{5}\right) \\
& d_{33}=c_{01}+2 c_{02}+c \\
& d_{34}=d_{43}=0 \\
& d_{44}=c_{01}\left(l_{1}+l_{2}-l_{6}\right)+2 c_{02}\left(l_{3}+l_{4}+l_{6}\right)+c
\end{aligned}
$$

The rigidity matrix $[\mathrm{B}]$ is constructed similarly to the damping matrix. However, if the rigidity coefficients are assumed to be constant, the damping coefficients are a velocity function of the rod movement relative to the damper housing (Fig. 4).

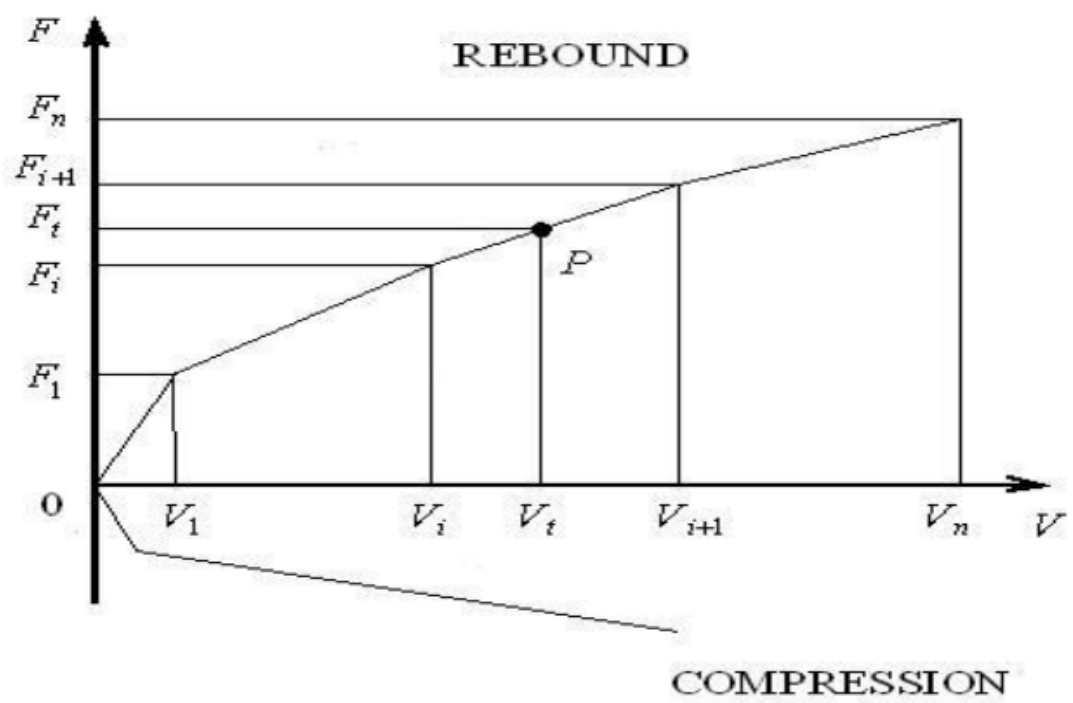

Figure. 4 :the damper housing 
Calculation of parameters of dampers in the mathematical model of the AGS is made by approximation of diagrams of real speed characteristics by piecewise-linear dependencies. The current value of the damping coefficient is calculated at each integration step of the system of equations for the relation (8) accompanied by testing the "failure" conditions of dampers for geometrical constraints of the rod movement relative to the body, such as the forefront of the damper:

$$
c_{01}=\left[F_{i}+\left(F_{i+1}-F_{i}\right)\left(V_{t}-V_{i}\right) /\left(V_{i+1}-V_{i}\right)\right] / V_{t}
$$

The nature of impact on the ASG by uneven ground depends on many factors and, therefore, a mathematical description of such effects should consider the characteristics of the real movement. It is customary to consider the surface nature from the following perspectives [3]:

- changes in the surface pattern in the vertical plane are deterministic;

- the surface pattern is considered as a random function.

In the deterministic approach, the surface pattern is a combination of individual irregularities with certain parameters (height, length, shape, repetition frequency). If the irregularity is individual (bump, pit), then the equation for the ordinates can be written as

$$
u=u_{0}(1-\cos 2 \pi x / \lambda),
$$

where $u_{0}$ is the ordinate amplitude of unevenness with respect to the median line; $x$ is current coordinate in the direction of the ASG movement, $\lambda$ is the length of irregularity wave.

In case of accidental approach to the description of the surface pattern, the law of normal distribution of ordinates is commonly used, and the expression for the spectral density of surface irregularities $S_{u}$ (it characterizes the dominant frequencies in the spectrum of external loads) can be written as

$$
S_{u}(\theta)=\frac{a}{\theta^{b}}
$$

where e $\theta=\omega / v$ is spatial frequency; $\omega$ is cyclic frequency of oscillations; $v$ is speed of ASG movement; $a$ and $b$ are parameters that characterize the level of irregularities and their distribution by spatial frequencies.

Uneven surface relief acts on the ski-wheel system and causes its complex movement, which can be reduced to two simple movements - progressive vertical movement and rotation relative to the center of mass. It should be noted that due to the snow pliability and inclined shape of the forefront of the ski-wheel system, the trajectory of the center of mass of the skiwheel system does not correspond to the surface pattern. Therefore, a dynamic effect on the ASG when driving can be mathematically modeled by specifying the vertical movements and rotation angles of the ski-wheel system. To determine the force $F_{L}(t)$ and the torque $T_{L}(t)$ applied to the ski-wheel system at any one time, we use the relations

$$
F_{L}(t)=k y(t) ; T_{L}(t)=k \alpha(t) \text {, }
$$

Where $t$ is time; $k$ is rigidity coefficients characterizing the elastic interaction of the skiwheel system with the surface. 


\section{SOLUTION OF THE PROBLEM AND RESULTS}

Calculation of the ASG movement through the obstacle's "bump", "step", "and uneven surface" was performed using the developed software package based on the ratios described above. The program allows changes in geometry, inertial, elastic and damping characteristics, speed of the ASG, geometric parameters of obstacles, etc., which makes it possible to analyze the effect of each of these parameters on the process of dynamic loading of the model.

As an example, Fig. 5 shows the result of simulation of dynamic loading of the AGS when driving through a local obstacle with the parameters: $h=2 u_{0}=0.5 \mathrm{~m}, \lambda=5 \mathrm{~m}, v=20 \mathrm{~m} / \mathrm{s}$.

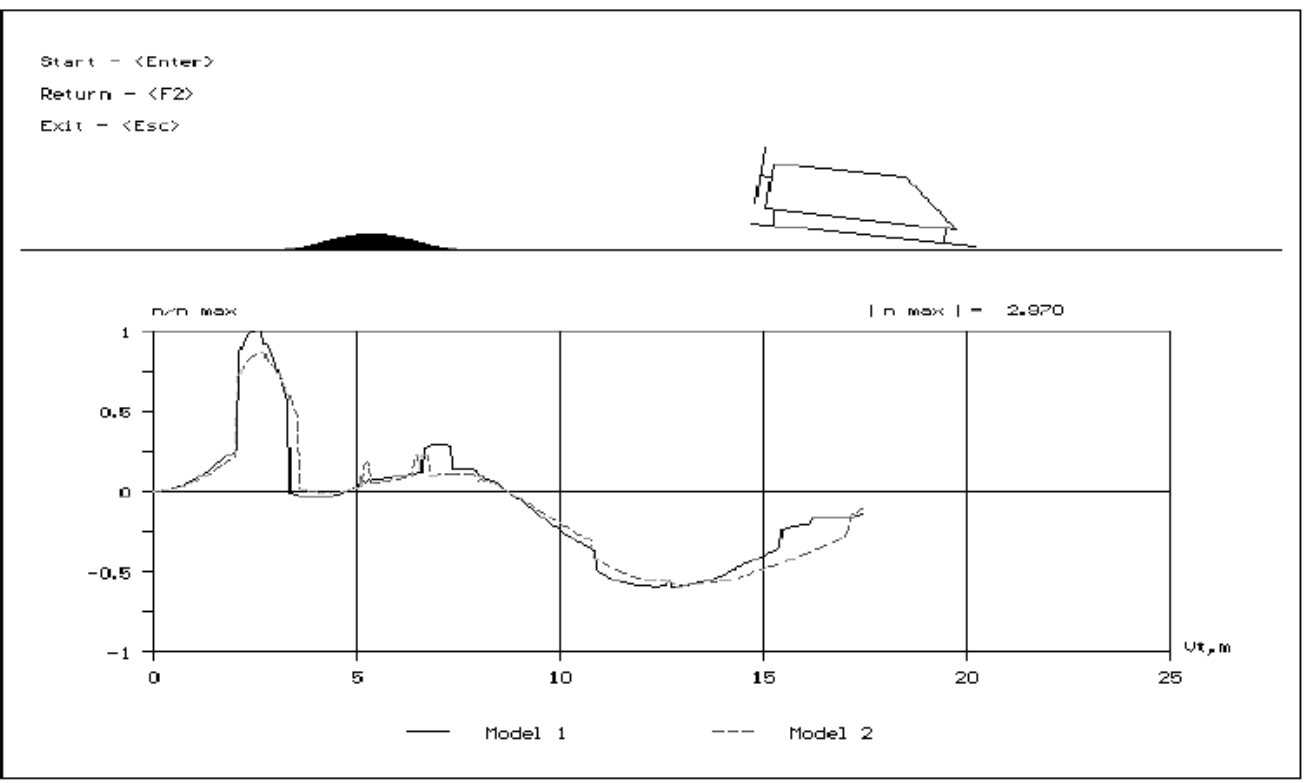

Figure. 5: the result of simulation of dynamic loading of the AGS when driving through a local obstacle with the parameters

The diagrams in this example show relative vertical accelerations at the point of placement of the AGS driver for two calculation cases, differing in cab loading (model 1 - a single driver model 2 - a driver and two passengers). A user can output to the screen other kinematic or dynamic characteristics at any point of the structure as a function of time.

The numerical research into dynamic characteristics of the ASG when moving over uneven surfaces was conducted in the form of numerical experiments for different values of travel speed, ASG loading and parameters of obstacles. The maximum relative vertical accelerations (overloads) in the driver's location for six models of serial dampers (shock absorbers) [4] are shown in Fig. 6. 


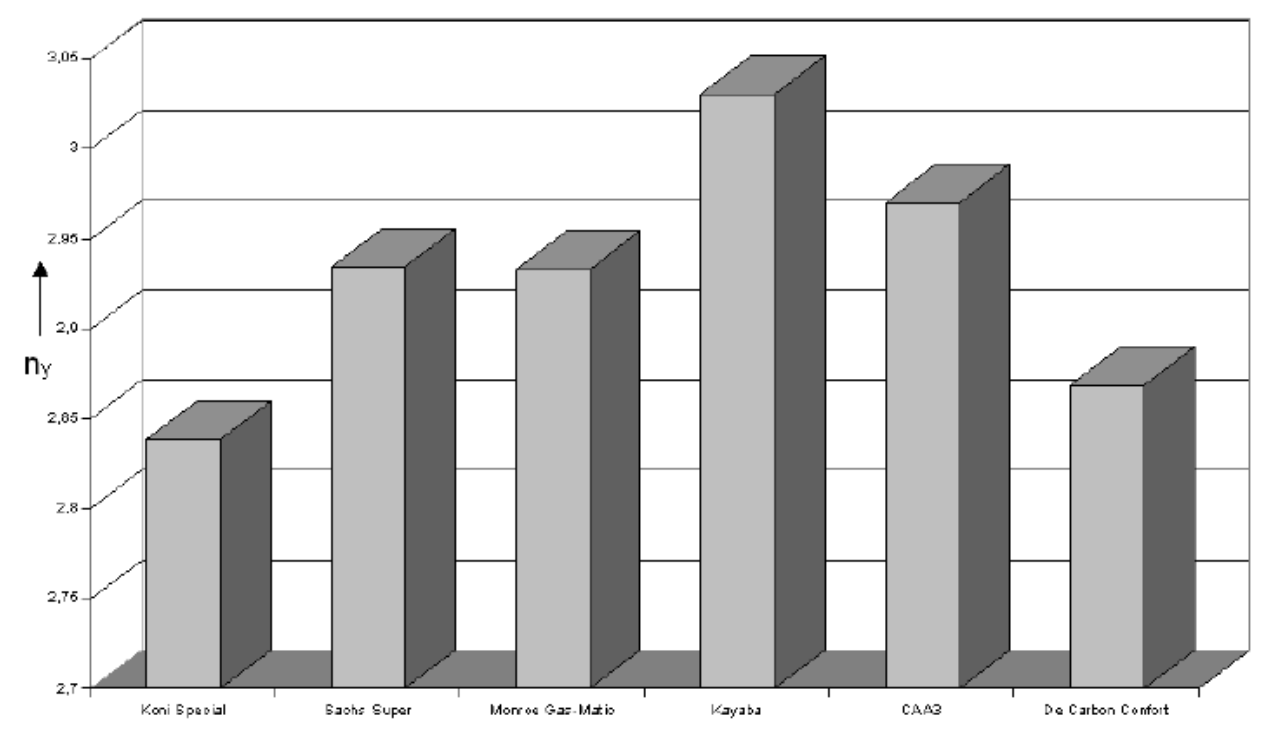

Figure. 6: The maximum relative vertical accelerations (overloads) in the driver's location for six models of serial dampers (shock absorbers)

The accumulated array of results was subject to mathematical processing to optimize the suspension performance by the criterion of minimization of vertical accelerations for a wide range of obstacles' parameters, travel speeds and the ASG loading of AW. This, in turn, allowed developing specific recommendations on the selection and configuration of elastic damping suspension assemblies for the ASG prototype.

\section{DISCUSSION OF RESULTS}

We designed the calculation scheme and the mathematical model of dynamic loading for the ASG with elastic damping cab suspension. This approach was implemented as a software package for a $\mathrm{PC}$ with visualization of calculation results.

Based on parametric studies in the numerical experiment and optimization of the ASG elastic damping suspension components we developed recommendations on the choice of their characteristics to reduce the dynamic loads that arise in the course of movement, increase the comfort of the driver and passengers.

\section{REFERENCES}

[1] Forsythe G.E., Malcolm M.A. \& Moler C.B. Computer methods for mathematical computations, Prentice-Hall, Inc.: Englewood Cliffs, 1977.

[2] Hashamdar H., Ibrahim Z. \& Jamee M. (Journal). Finite element analysis of nonlinear structures with Newmark method // International Journal of the Physical Sciences Vol. 6(6), pp 1395-1403 Dec 2011.

[3] Ostashov V.G. \& Sandler L.B. Glissirujushhie snegohody-amfibii [Amphibious snowmobile-gliders]. - Novosibirsk: GALATEJa, 164 p Dec 1991(in Russian).

[4] Voskresenskij S., Golovanov L. Amortizatory: svidanie vslepuju [Dampers: Blind Date] // Avtorevju 15. - p. 28-30 Dec 1996 (in Russian). [Auto Review].

[5] Yudakov A.A \& Boikov V.G. 1, Numerical methods of multibody mechanical system's dynamic equations integration, based on methods of direct integration of finite element method's dynamic equations // Bulletin of Udmurt University. Mathematics, Mechanics, Computer Science. pp. 131-144 Dec 2013 (Journal) 
Numerical Modeling of Amphibious Snowmobile-Glider Movement on Uneven Surface

[6] Alka Chaudhary, V N Tiwari and Anil Kumar, A Detailed Study of Routing Protocols for Mobile Ad Hoc Networks Using Qualnet Simulator, International Journal of Electronics and Communication Engineering \& Technology (IJECET), Volume 4, Issue 7 (2013), pp. 182-189.

[7] Hassan Charaf, A Methodology for Model-Driven Multiplatform Mobile Application Development, International Journal of Computer Engineering and Technology (IJCET), Volume 4, Issue 1, January- February (2013), pp. 61-70.

[8] Ankur Bhushan, A Comparative Analysis of Consumer Behavior of Nokia \& Samsung Mobile Users. International Journal of Management, 7(6), 2016, pp. 140-144. 